\title{
Germline ablation of VGF increases lipolysis in white adipose tissue
}

\author{
Samira Fargali ${ }^{1}$, Thomas Scherer ${ }^{2,+}$, Andrew C Shin ${ }^{2}$, Masato Sadahiro ${ }^{1}$, Christoph Buettner ${ }^{1,2}$ \\ and Stephen R Salton ${ }^{1,3}$ \\ Departments of ${ }^{1}$ Neuroscience, ${ }^{2}$ Medicine and ${ }^{3}$ Geriatrics, Box 1065, Mount Sinai School of Medicine, One Gustave L. Levy Place, New York, \\ New York 10029, USA \\ (Correspondence should be addressed to S R Salton at Department of Neuroscience, Box 1065; Email: stephen.salton@mssm.edu) \\ ${ }^{\dagger}$ (T Scherer is now at Division of Endocrinology and Metabolism, Department of Internal Medicine III, Medical University of Vienna, Waehringer Guertel 18-20, \\ 1090 Vienna, Austria)
}

\begin{abstract}
Targeted deletion of VGF, a neuronal and endocrine secreted protein and neuropeptide precursor, produces a lean, hypermetabolic mouse that is resistant to diet-, lesion-, and genetically induced obesity and diabetes. We hypothesized that increased sympathetic nervous system activity in $V g f-/ V g f-$ knockout mice is responsible for increased energy expenditure and decreased fat storage and that increased $\beta$-adrenergic receptor stimulation induces lipolysis in white adipose tissue (WAT) of $V g f-/ V g f-$ mice. We found that fat mass was markedly reduced in $V g f-/ V g f-$ mice. Within knockout WAT, phosphorylation of protein kinase A substrate increased in males and females, phosphorylation of hormone-sensitive lipase (HSL) (ser563) increased in females, and levels of adipose triglyceride lipase, comparative gene identification-58, and phosphoperilipin were higher in male $V g f-/ V g f-$ WAT compared
\end{abstract}

with wild-type, consistent with increased lipolysis. The phosphorylation of AMP-activated protein kinase (AMPK) (Thr172) and levels of the AMPK kinase, transforming growth factor $\beta$-activated kinase 1 , were decreased. This was associated with a decrease in HSL ser565 phosphorylation, the site phosphorylated by AMPK, in both male and female $V g f-/ V g f-$ WAT. No significant differences in phosphorylation of CREB or the p42/44 MAPK were noted. Despite this evidence supporting increased cAMP signaling and lipolysis, lipogenesis as assessed by fatty acid synthase protein expression and phosphorylated acetyl-CoA carboxylase was not decreased. Our data suggest that the VGF precursor or selected VGF-derived peptides dampen sympathetic outflow pathway activity to WAT to regulate fat storage and lipolysis.

Journal of Endocrinology (2012) 215, 313-322

\section{Introduction}

The sympathetic nervous system (SNS) is an important regulator of glucose and fat metabolism, and its dysfunction can predispose to obesity and type 2 diabetes mellitus. The melanocortin pathway projects from the hypothalamic paraventricular nucleus, innervating parasympathetic and sympathetic preganglionic cells in the brainstem and spinal cord, to form sympathetic circuits that innervate brown adipose tissue (BAT), white adipose tissue (WAT), liver, and pancreas (Giordano et al. 2005, Song et al. 2005, Penn et al. 2006, Voss-Andreae et al. 2007, Foster et al. 2010). This pathway, through its modulation of autonomic outflow, has been proposed to regulate food intake, energy expenditure, and insulin secretion (Bray \& York 1998, Friedman \& Halaas 1998, Fan et al. 2000, Li et al. 2003). Norepineprine, released from sympathetic nerve endings, stimulates lipolysis in WAT and increases thermogenesis in BAT via activation of $\beta$-adrenergic receptors (Collins et al. 2004), and mice that lack all three $\beta$-adrenergic receptor subtypes (betaless) develop massive diet-induced obesity (Bachman et al. 2002).

VGF is a secreted protein and peptide precursor, a member of the chromogranin/secretogranin family (Bartolomucci et al. 2011), which is expressed in neurons throughout the brain and in several neuroendocrine and endocrine tissues (Salton et al. 2000, Levi et al. 2004). Homozygous germline $V g f$ knockout mice are lean and hypermetabolic and resist developing obesity and diabetes when fed a high-fat diet (Hahm et al. 1999), suggesting that VGF regulates energy balance by modulating sympathetic outflow. Consistent with this hypothesis, neonatal treatment of $V g f-/ V g f-$ mice with either monosodium glutamate, which damages the hypothalamus and the hypothalamic projections to the autonomic nervous system (Bergen et al. 1998, Morris et al. 1998, Tsukahara et al. 1998), or guanethidine, which results in a peripheral sympathectomy (Watson et al. 2009), blocks development of the lean phenotype (Hahm et al. 2002, Watson et al. 2005). Moreover, Vgf knockout mice have also 
increased serum-free fatty acid (FFA) levels, suggesting increased fat mobilization in WAT (Watson et al. 2005). Targeted deletion of $V g f$ also suppresses obesity, hyperinsulinemia, and hyperglycemia in $\mathrm{A}^{\mathrm{y}} / \mathrm{a}$ agouti and melanocortin 4 receptor-deficient $(M c 4 r-/ M c 4 r-)$ mice (Hahm et al. 2002, Watson et al. 2005), supporting a role for VGF in the melanocortin pathway and its projections. Here, we examined WAT to determine the effect that targeted germline ablation of VGF has on the activation state and the protein expression of key lipolytic and lipogenic enzymes. We noted alterations in the level and/or phosphorylation of proteins that control fat breakdown, consistent with increased SNS activity. Our studies support the hypothesis that VGF and/or one or more VGF peptides modulate sympathetic outflow pathway activity to control fat storage and energy expenditure.

\section{Materials and Methods}

\section{Mouse strains and diets}

The VGF-deficient line used here was generated by Regeneron Pharmaceuticals, Inc. (Tarrytown, NY, USA) as described previously (Valenzuela et al. 2003) using F1H4 ES cells (a 129B6/F1-derived cell line) and a BAC-based targeting vector with deletion of the entire $V g f$ coding sequence and insertion of an in-frame lac $Z$ reporter gene and neomycin selection cassette; chimeric mice resulted from the injection of two independent $V g f-/ V g f-$ embryonic stem cell clones into C57BL6/J blastocysts. Male chimeras were mated with C57BL6/J females to produce F1 breeders and experiments were performed on N2F1 mice ( $>83 \%$ C57Bl6 background). As described previously (Watson et al. 2009), the phenotype of the Regeneron VGF-deficient line is extremely similar to an earlier line generated using R1 ES cells (Hahm et al. 1999). Mice were housed at room temperature in a $12 \mathrm{~h}$ light: $12 \mathrm{~h}$ darkness cycle with chow and water available ad libitum unless otherwise specified. Mice fed standard chow received a $4.5 \%$ fat, $55 \%$ carbohydrate, $20 \%$ protein, and $4.7 \%$ fiber diet (Purina PicoLab Rodent Diet 20-5053; 4 kcal/g; Purina, St Louis, MO, USA). All animal studies were conducted in accordance with the Guide for Care and Use of Experimental Animals, using protocols approved by Institutional Animal Care and Use Committees at Mount Sinai School of Medicine.

\section{Western blot analysis}

Gonadal WAT from wild-type $(V g f+/ V g f+)$, heterozygous knockout $(V g f+/ V g f-)$, and homozygous knockout $(V g f-/ V g f-)(n=4-17)$ mice was homogenized in ice-cold lysis buffer. Two different buffers were used with comparable results: i) $50 \mathrm{mM}$ Tris $-\mathrm{HCl}(\mathrm{pH}$ 8), $150 \mathrm{mM} \mathrm{NaCl}, 0 \cdot 1 \%$ SDS, $0.5 \%$ deoxycholate, and 1\% NP40 supplemented with protease and phosphatase inhibitor cocktails (Roche Diagnostics; Thermo Scientific, Waltham, MA, USA;
Watson et al. 2009) and ii) $20 \mathrm{mM}$ MOPS, $2 \mathrm{mM}$ EGTA, $5 \mathrm{mM}$ EDTA, $30 \mathrm{mM}$ sodium fluoride, $40 \mathrm{mM} \beta$-glycerophosphate, $10 \mathrm{mM}$ sodium pyrophosphate, $2 \mathrm{mM}$ sodium orthovanadate, $0.5 \%$ NP-40, and complete protease inhibitor cocktail (Roche; Scherer et al. 2011). Lysates were cleared by centrifugation $\left(16800 \mathrm{~g}, 10 \mathrm{~min}\right.$ at $\left.4{ }^{\circ} \mathrm{C}\right)$, and the protein concentration of the supernatant was determined by the BCA protein method (Thermo Scientific). Protein samples $(25 \mu \mathrm{g})$ were separated by SDS-PAGE and transferred to PVDF membranes (Millipore, Bedford, MA, USA). Membranes were blocked with $5 \%(\mathrm{w} / \mathrm{v}) \mathrm{BSA}$ in PBS or with Odyssey LI-COR Blocking Buffer (LI-COR, Lincoln, NE, USA) 1:1 in TBS.

Membranes were incubated overnight at $4{ }^{\circ} \mathrm{C}$ with the following rabbit antisera (Cell Signaling, Boston, MA, USA), unless otherwise indicated, diluted in blocking buffer: phospho-AMP-activated protein kinase (AMPK $\alpha$ ) (Thr172) $(1: 1000(\mathrm{v} / \mathrm{v}))$, total AMPK $\alpha(1: 1000(\mathrm{v} / \mathrm{v}))$; TAK1 $(1: 1000$ $(\mathrm{v} / \mathrm{v}))$, mouse monoclonal anti-GAPDH $(1: 1000(\mathrm{v} / \mathrm{v}))$, phospho-TAK1 (Thr187) $(1: 1000(\mathrm{v} / \mathrm{v}))$, transducer of regulated CREB activity 3 (TORC3) (1:1000 (v/v)), phospho-hormone-sensitive lipase (HSL) ser563 (1:1000 $(\mathrm{v} / \mathrm{v}))$, phospho-HSL ser565 (1:1000 (v/v)), phospho-HSL ser660 $(1: 1000(\mathrm{v} / \mathrm{v}))$, HSL total $(1: 2000(\mathrm{v} / \mathrm{v}))$, ATGL $(1: 1000(\mathrm{v} / \mathrm{v}))$, phospho-protein kinase A (PKA) substrate $(1: 1000(\mathrm{v} / \mathrm{v}))$, phospho-acetyl CoA carboxylase (ACC) $(1: 1000(\mathrm{v} / \mathrm{v}))$, ACC $(1: 1000(\mathrm{v} / \mathrm{v})), \mathrm{p} 42 / 44$ MAPK $(1: 1000$ $(\mathrm{v} / \mathrm{v}))$, phospho-p42/44 MAPK (1:1000 (v/v)), GLUT4 $(1: 1000(\mathrm{v} / \mathrm{v}))$, and phospho-CREB $(1: 1000(\mathrm{v} / \mathrm{v}))$. Other antisera included FAS $(1: 1000(\mathrm{v} / \mathrm{v}))(\mathrm{BD}$ Bioscience, San Jose, CA, USA), insulin receptor $\beta(1: 500(\mathrm{v} / \mathrm{v}))$ (Santa Cruz Biotechnology, Santa Cruz, CA, USA), $\beta$-actin (1:10 000 $(\mathrm{v} / \mathrm{v}))$ (Abcam, Cambridge, MA, USA), GADPH (1:5000 $(\mathrm{v} / \mathrm{v}))($ Abcam), perilipin $(1: 2000(\mathrm{v} / \mathrm{v}))$ (Souza et al. 2002) (gift from Dr Andrew Greenberg, Tufts University, MA), and CGI-58 (1:2000 (v/v)) (Subramanian et al. 2004) (gift from Dawn Brasaemle, Rutgers University, NJ, USA).

After three consecutive 5 min washes in PBS-T or TBS-T $(0 \cdot 1 \%$ Tween 20 in PBS or TBS respectively), membranes were incubated for $1 \mathrm{~h}$ at room temperature with either HRP-conjugated secondary antibody $(1: 2000(\mathrm{v} / \mathrm{v})$ in PBS-T; GE Healthcare, Piscataway, NJ, USA) containing $5 \%$ nonfat dry milk or with Dylight 680-conjugated goat anti-rabbit IgG and Dylight 800-conjugated goat anti-mouse IgG (both Thermo Scientific) in blocking buffer containing $0 \cdot 1 \%$ TBS-T and $0 \cdot 1 \%$ SDS. After three washes in PBS-T or TBS-T, bound antibodies were detected using either ECL (Thermo Scientific), exposure to HyBlot CL (Denville Scientific, Metuchen, NJ, USA), and densitometric quantification using NIH ImageJ or were scanned with the LI-COR Odyssey (LI-COR) and quantified with Odyssey 3.0 software based on direct fluorescence measurement.

\section{Data and statistical analysis}

Data are expressed as mean \pm s.E.M. The statistical significance of differences among $V g f-/ V g f-, V g f-/ V g f+$, and 
$V g f+/ V g f+$ groups was subjected to a one-way ANOVA and Tukey's multiple-range test; comparisons were performed using Prism 5.0 (GraphPad Software, Inc., La Jolla, CA, USA). $P$ values $<0.05$ were considered significant. For western blot assays, values ( \pm s.E.M.) from $V g f-/ V g f-$ and $V g f+/ V g f+$ adipose samples were compared by two-tailed Student's $t$-test.

\section{Results}

$\mathrm{Vgf}-/ \mathrm{Vgf}-$ knockout mice showed significantly reduced body and gonadal fat pad weights compared with $\mathrm{Vgf}+/ \mathrm{Vgf}-$ and $\mathrm{Vgf}+/ \mathrm{Vgf}+$ mice

Quantification of $V g f-/ V g f-, \quad V g f+/ V g f-, \quad$ and $V g f+/ V g f+$ body and adipose tissue weights was initially performed. Because fat mass is often dramatically reduced in homozygous $V g f$ knockout mice, only gonadal WAT could be reliably isolated and quantified from all mice. $V g f-/ V g f-$ male and female mice are lean with 42 and 31\% less body weight respectively than $V g f+/ V g f+$ mice (Fig. $1 \mathrm{~A}$ and $\mathrm{B}$ ), which was accompanied by a significant eightfold decrease in gonadal fat pad mass (Fig. 1F, $\star \star \star P<0 \cdot 0001$, ANOVA), which was also significantly decreased when fat pad mass was examined as a percentage of body mass (Fig. 1I, $\star \star \star P<0 \cdot 0001$, ANOVA). In addition, similar differences between $V g f-/ V g f+$ heterozygous and $V g f-/ V g f-$ mice were noted (Fig. 1C, $\star \star \star P<0 \cdot 0001$, ANOVA). Neither body weight nor fat pad weight differed significantly between $V g f-/ V g f+$ and $V g f+/ V g f+$ mice. Photographs of representative 8 -week-old female mice of each genotype, and adipose depots dissected from each, are shown in Fig. 1J, $\mathrm{K}, \mathrm{L}, \mathrm{M}, \mathrm{N}, \mathrm{O}, \mathrm{P}, \mathrm{Q}$ and $\mathrm{R}$.

\section{Altered protein expression in $\mathrm{Vgf}-/ \mathrm{Vgf}-W A T$ is consistent with increased lipolysis}

Western analysis of adipose tissues from $V g f-/ V g f-$, $V g f+/ V g f-$, and $V g f+/ V g f+$ mice was performed to investigate potential mechanisms underlying decreased adiposity in $V g f$ knockout mice. Expression of proteins involved in glucose uptake or lipogenesis was unchanged: GLUT4, the main transporter involved in glucose uptake into WAT, fatty acid synthase (FAS), and additional enzymes important in adipose tissue triglyceride accumulation, including total and phosphorylated ACC, were unchanged in $V g f$ knockout WAT compared with wild-type (Table 1).

Next, we analyzed whether reduced gonadal fat pad weight might be due to increased lipolysis. Phosphorylation of HSL, an enzyme responsible for the mobilization of FFAs from adipose tissue, on serine 563 was significantly increased in female $V g f-/ V g f-$ WAT (Fig. 2A), although phosphorylation of HSL at serine 660 was unchanged (Fig. 2B). We found that levels of adipose triglyceride lipase (ATGL), the main lipase responsible for the first step in intracellular triglyceride hydrolysis, were significantly upregulated in male $V g f-/ V g f-$ WAT (Fig. 2C). This was consistent with increased expression of comparative gene identification-58 (CGI-58, also known as a/b hydrolase domain containing protein 5; Fig. 2D) and increased levels of phospho-perilipin (Fig. 2E), both important activators of ATGL-mediated lipolysis, in male $V g f$ knockout WAT.

AMPK, an enzyme that is regulated by phosphorylation, has been implicated in the regulation of HSL. Phosphorylation of AMPK $\alpha$, the catalytic subunit of AMPK, was significantly reduced in $V g f-/ V g f-$ relative to $V g f+/ V g f+$ WAT (Fig. 3A; $\star \star \star P=0 \cdot 0001)$. In support of these findings, previous studies noted that activation of AMPK decreased HSL phosphorylation of ser563, while dominant negative inhibitors or targeted ablation of AMPK increased phosphoHSL (563) levels in adipocytes (Daval et al. 2005). Levels of transforming growth factor $\beta$-activated kinase 1 (TAK1), a MAPK kinase kinase, and AMPK kinase (Momcilovic et al. 2006, Xie et al. 2006), decreased in $V g f-/ V g f-$ WAT (Fig. 3B; ${ }^{\star} P=0 \cdot 0207$ ). Although we were unable to detect TAK1 (Thr187) phosphorylation in our WAT samples, phosphorylation of HSL at serine 565, a downstream target of AMPK (Anthonsen et al. 1998), was found to be significantly decreased in $V g f-/ V g f-$ WAT (Fig. 3C; $\star \star P=0 \cdot 0039)$, suggesting reduced activation of AMPK in male and female $V g f$ knockout WAT. In addition, the overall pattern of phosphorylation of PKA substrate (Fig. 3D) was significantly increased in male and female $V g f-/ V g f-$ WAT, consistent with increased PKA activity.

No changes in the expression of p42/44 MAPK were detected (Table 1), which is consistent with our finding that phosphorylation of HSL at serine 660 was not altered; phosphorylation at serine 660 by p42/44 MAPK enhances the enzymatic activity of HSL (Greenberg et al. 2001). Levels of perilipin, a protein associated with the lipid droplet, were not changed (Table 1). Lastly, no significant differences in the levels of phosphorylated CREB (pCREB), its coactivator TORC3, or the insulin receptor protein IR $\beta$ were noted between $V g f-/ V g f-$ and $V g f+/ V g f+$ WAT (Table 1).

\section{Discussion}

We examined the effect that targeted germline $V g f$ gene ablation has on fat pad weight and WAT lipolysis and lipogenesis. Characterization of $V g f$ knockout mice previously revealed increased circulating FFA levels, consistent with increased lipolysis (Watson et al. 2005). Here, we found that $V g f$ knockout mice have reduced body weight, decreased gonadal fat pad weight, and alterations in a number of key lipolytic proteins by western blot analysis compared with wild-type mice. Phosphorylation of HSL on serine 563, which activates the enzyme, was increased in $V g f$ knockout mice in comparison with wild-type mice, significantly in females. This site is generally phosphorylated by PKA (Anthonsen et al. 1998), and consistent with increased PKA 
A

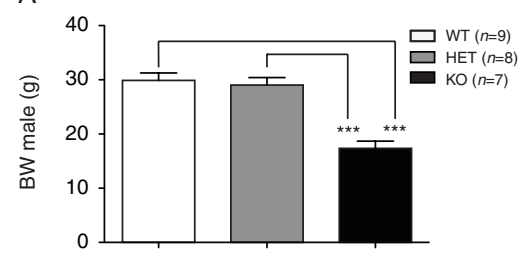

B

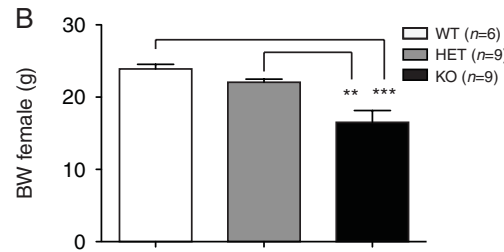

C
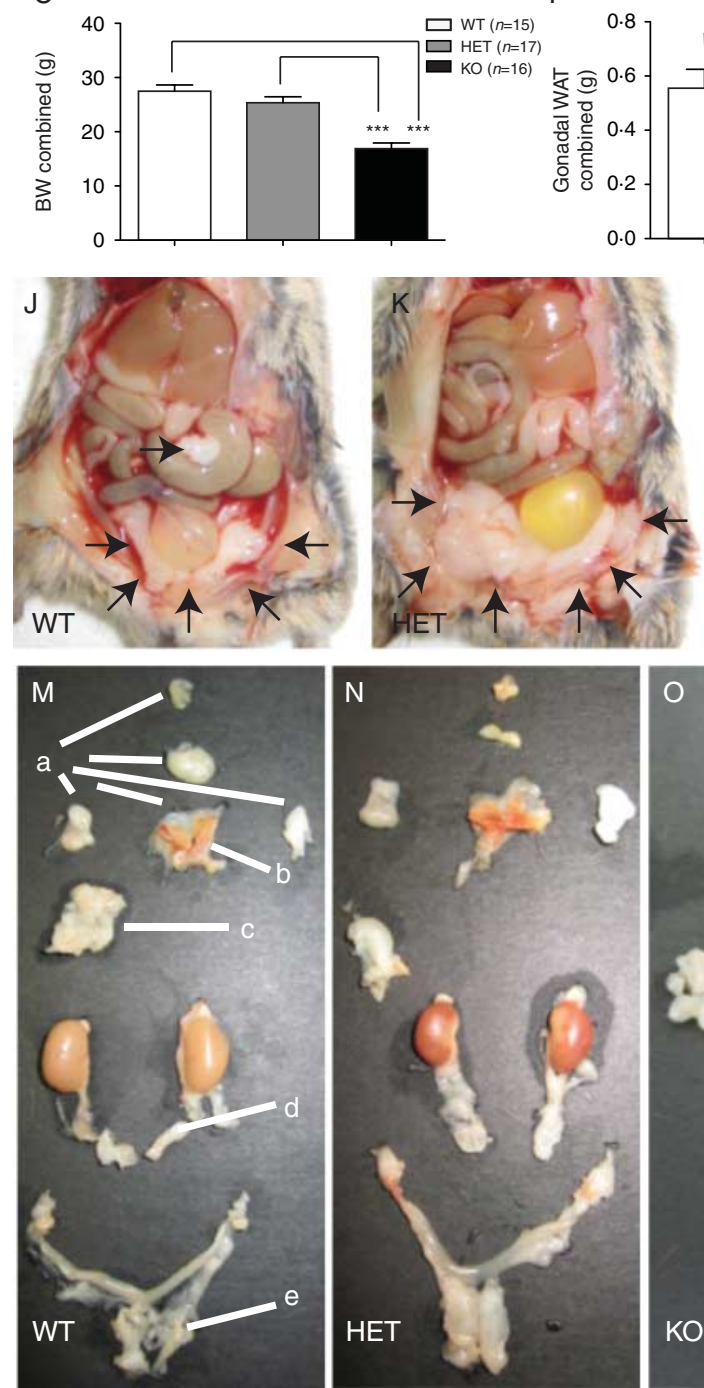

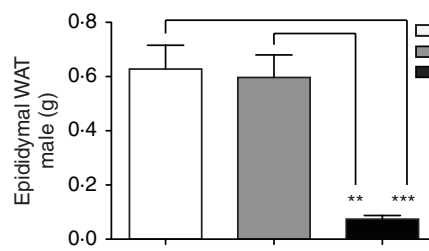

$E$

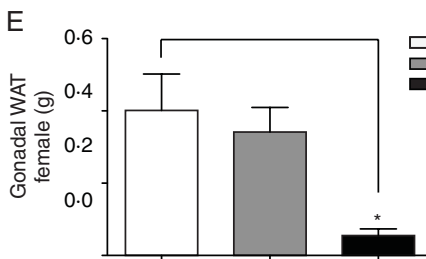

$\mathrm{F}$
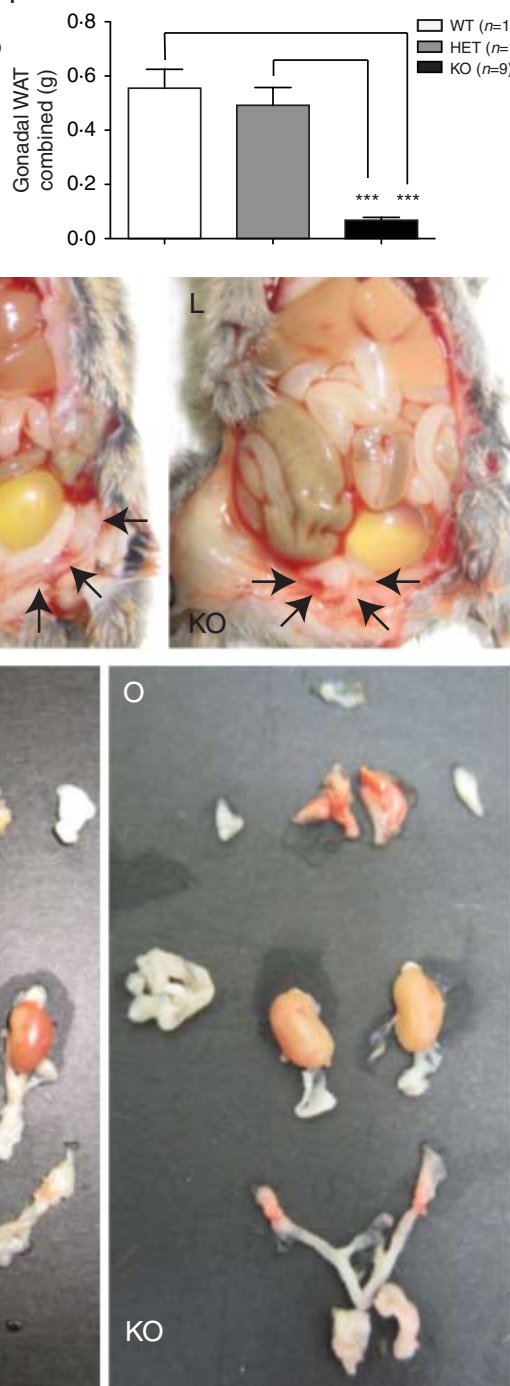

G
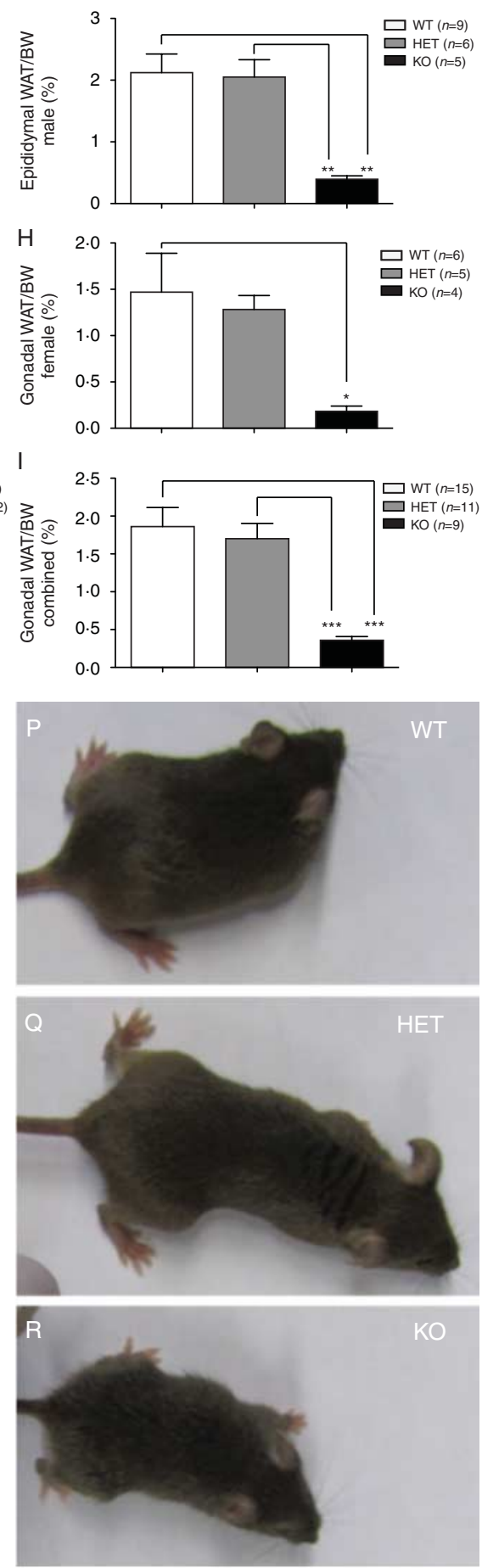
Table 1 Expression of proteins that regulate lipolysis or lipogenesis: comparison of $V g f$ knockout and wild-type gonadal WAT. Protein levels were determined in gonadal fat pads from 9-10-week-old male and female mice using western blot analysis as described in the Materials and Methods section. All data are normalized to the loading control $\beta$-actin and are expressed in arbitrary units (mean \pm s.E.M.); statistical significance was determined using the two-tailed Student's $t$-test with $P<0 \cdot 05$ considered significant (male, $n=3-6(V g f+N g f+), n=3-5$ $(V g f-N g f-)$; female, $n=3-4(V g f+N g f+), n=3-5(V g f-N g f-))$. No significant differences in the levels of these proteins were found between $V g f-N g f-$ and $V g f+N g f+$ WAT

\begin{tabular}{|c|c|c|c|c|c|}
\hline $\begin{array}{l}\text { Protein quantified } \\
\text { in male WAT }\end{array}$ & $\begin{array}{l}\text { Protein expression } \\
\text { (arbitrary units) } \\
\text { mean } \pm \text { s.E.M. }\end{array}$ & $P$ value & $\begin{array}{l}\text { Protein quantified in } \\
\text { female WAT }\end{array}$ & $\begin{array}{l}\text { Protein expression } \\
\text { (arbitrary units) } \\
\text { mean } \pm \text { s.E.M. }\end{array}$ & $P$ value \\
\hline FAS & $\begin{array}{l}V g f+/+=0 \cdot 19 \pm 0 \cdot 21 \\
V g f-/-=0 \cdot 17 \pm 0 \cdot 06\end{array}$ & 0.93 & FAS & $\begin{array}{l}\operatorname{Vgf}+/+=0 \cdot 27 \pm 0 \cdot 04 \\
\operatorname{Vgf}-/-=0.37 \pm 0 \cdot 11\end{array}$ & $0 \cdot 45$ \\
\hline Perilipin & $\begin{array}{l}V g f+/+=0.46 \pm 0.12 \\
V g f-/-=0.55 \pm 0.05\end{array}$ & 0.62 & Perilipin & $\begin{array}{l}\vee \mathrm{gf}+/+=1 \cdot 14 \pm 0 \cdot 22 \\
\operatorname{Vgf}-/-=1 \cdot 01 \pm 0 \cdot 32\end{array}$ & 0.79 \\
\hline TORC3 & $\begin{array}{l}\vee g f+/+=0 \cdot 015 \pm 0 \cdot 003 \\
\operatorname{Vgf}-/-=0 \cdot 017 \pm 0 \cdot 002\end{array}$ & 0.55 & TORC3 & $\begin{array}{l}V \mathrm{gf}+/+=0 \cdot 03 \pm 0 \cdot 01 \\
\operatorname{Vgf}-/-=0 \cdot 04 \pm 0 \cdot 01\end{array}$ & $0 \cdot 58$ \\
\hline $\operatorname{IR} \beta$ & $\begin{array}{l}\vee g f+/+=0 \cdot 06 \pm 0.003 \\
\operatorname{Vgf}-/-=0.08 \pm 0.02\end{array}$ & $0 \cdot 55$ & $\operatorname{IR} \beta$ & $\begin{array}{l}V g f+/+=0 \cdot 05 \pm 0 \cdot 01 \\
V g f-/-=0 \cdot 07 \pm 0 \cdot 02\end{array}$ & $0 \cdot 57$ \\
\hline ACC & $\begin{array}{l}\text { Vgf }+/+=0 \cdot 008 \pm 0 \cdot 002 \\
\operatorname{Vgf}-/-=0 \cdot 074 \pm 0 \cdot 046\end{array}$ & $0 \cdot 23$ & ACC & $\begin{array}{l}\text { Vgf }+/+=0.114 \pm 0.06 \\
\operatorname{Vgf}-/-=0.077 \pm 0.02\end{array}$ & $0 \cdot 63$ \\
\hline pACC & $\begin{array}{l}\text { Vgf }+/+=0 \cdot 15 \pm 0 \cdot 061 \\
\text { Vgf }-/-=0 \cdot 42 \pm 0 \cdot 146\end{array}$ & $0 \cdot 16$ & pACC & $\begin{array}{l}\operatorname{Vgf}+/+=0 \cdot 39 \pm 0 \cdot 104 \\
\operatorname{Vgf}-/-=0 \cdot 22 \pm 0 \cdot 045\end{array}$ & $0 \cdot 19$ \\
\hline GLUT4 & $\begin{array}{l}\operatorname{Vgf}+/+=0 \cdot 03 \pm 0 \cdot 006 \\
\operatorname{Vgf}-/-=0 \cdot 04 \pm 0 \cdot 021\end{array}$ & $0 \cdot 58$ & GLUT4 & $\begin{array}{l}\vee g f+/+=0 \cdot 038 \pm 0 \cdot 009 \\
\text { Vgf }-/-=0.057 \pm 0.008\end{array}$ & $0 \cdot 20$ \\
\hline HSL total & $\begin{array}{l}\text { Vgf }+/+=0 \cdot 16 \pm 0 \cdot 017 \\
\operatorname{Vgf}-/-=0 \cdot 14 \pm 0 \cdot 060\end{array}$ & $0 \cdot 80$ & HSL total & $\begin{array}{l}\text { Vgf }+/+=0 \cdot 15 \pm 0 \cdot 061 \\
\text { Vgf }-/-=0 \cdot 076 \pm 0 \cdot 024\end{array}$ & $0 \cdot 32$ \\
\hline
\end{tabular}

activity, significant changes were noted in PKA substrate phosphorylation (Fig. 3D) in both male and female knockout WAT. In addition, we showed that the lipase ATGL, and its activators CGI-58 and phospho-perilipin, were significantly increased in WAT from male $V g f-/ V g f-$ mice. Recent studies have demonstrated that interaction of CGI-58 with ATGL enhances its activity up to 20-fold (Lass et al. 2006, Gruber et al. 2010), so taken together, our western blot results are consistent with increased lipolysis in $V g f$ knockout adipose tissue, although there may be some sex-specific differences that need further exploration.

The role that AMPK plays in regulating lipid storage in the adipocyte is incompletely understood. Phosphorylation of
HSL at serine 565 by AMPK reduces HSL phosphorylation at serine 563 by PKA, inhibiting HSL activity (Anthonsen et al. 1998), while a number of other studies have shown an inhibitory effect of AMPK on adipocyte lipolysis (Daval et al. 2005, Anthony et al. 2009, Gaidhu et al. 2009). Consistent with the former, we noted decreased pAMPK, decreased pHSL (ser565), and increased pHSL (ser563) in Vgf knockout WAT. The anti-lipolytic role of AMPK was demonstrated using adipocytes from $A m p k \alpha 1$-knockout mice, treatment of adipocytes with AMPK inhibitors, and transfection of dominant negative and constitutively active AMPK constructs into adipocytes (Daval et al. 2005). On the other hand, treatment of rodents with AMPK agonists is associated with

Figure 1 Body weight (BW) and gonadal WAT are reduced in $V g f$ knockout mice. BWs (g) of male and female $V g f-N g f-(K O), V g f+N g f-$ $(\mathrm{HET})$, and $V g f+N g f+(\mathrm{WT})$ mice were measured at 9 weeks of age (A, B, and C); male and female $V g f-N g f-$ mice had significantly lower BW compared with $V g f+N g f-$ and $V g f+N g f+$ mice. In D, gonadal fat pad weights $(g)$ were significantly reduced in $V g f-N g f-(n=5$ males, 4 females), compared with $V g f+N g f-(n=6$ males, 7 females $)$, and $V g f+N g f+(n=9$ male, 7 females $)$. No significant differences in BW, fat pad weight, or the ratio of fat pad weight to BW, between $V g f+N g f-$ and $V g f+N g f+$ mice, were noted (A, B, C, D, E, F, G, H and I). BWs and epididymal and ovarian fat pad weights were measured for each genotype at 9-10 weeks of age; values are mean \pm S.E.M., ${ }^{*} P=0 \cdot 0430,{ }^{*} P=0 \cdot 0031,{ }^{* * *} P<0 \cdot 0001$ compared with wild-type (WT) (ANOVA and Tukey's multiples comparison). Eight-week-old female mice ( $V g f+N g f+$ WT (24.6 g body weight), $V g f+N g f-$ HET $(20.5 \mathrm{~g})$, and $V g f-N g f-\mathrm{KO}(13.6 \mathrm{~g}))(\mathrm{P}, \mathrm{Q}$ and R respectively) were transcardially perfused with $4 \%$ paraformaldehyde in PBS, intraperitoneal fat depots were exposed (J indicated by arrows in, $K$ and $L$ ), and the subcutaneous and visceral depots were dissected and placed on a mouse template to show their location in the body ( $M, N$ and $O$ ). Fat depots are labeled with lower case letters: a (subcutaneous anterior: deep and superficial cervical, interscapular, subscapular, axillo-thoracic); b (interscapular BAT); c (mesenteric); d (perirenal, periovarian, parametrial, perivesical); e (subcutaneous posterior: dorsolumbar, inguinal, gluteal) (Murano et al. 2009). 

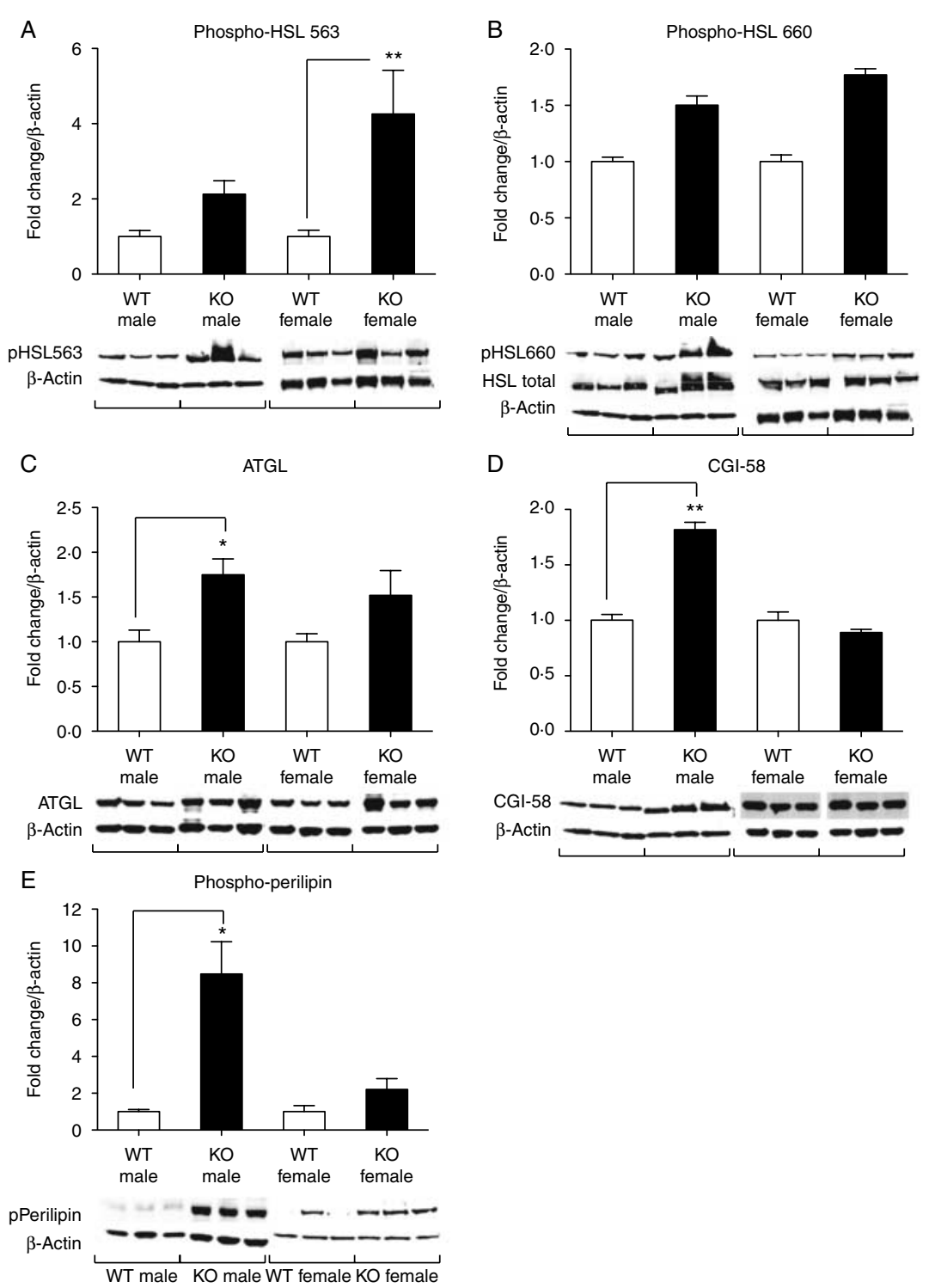

Figure 2 Altered expression of proteins involved in lipolysis in $\mathrm{Vg}$ knockout (KO) compared with wild-type (WT) WAT. WAT tissues were collected from $V g f-N g f-$ knockout mice $(n=11-13)$ and $V g f+N g f+$ wild-type littermate controls $(n=9-11)$, and protein expression was determined using western blot analysis and Image $\mathrm{J}$ as described in the Materials and Methods section. Values are expressed as fold change in knockout relative to wild-type WAT, normalized to $\beta$-actin as a loading control, and statistical significance was determined using the two-tailed Student's $t$-test $\left({ }^{*} P<0 \cdot 05\right)$. Levels of phospho-HSL (ser563) were significantly increased in Vgf KO WAT (A, $* * P=0 \cdot 0030)$, while phospho-HSL (ser660) levels were unchanged (B). Total HSL levels were also unchanged (see Table 1). Expression of ATGL $(\mathrm{C}, * P=0 \cdot 0312), \mathrm{CGI}-58(\mathrm{D}, * * P=0 \cdot 0074)$, and phospho-perilipin $(\mathrm{E}, * P=0 \cdot 0317)$ was significantly increased in Vgf knockout WAT.

leanness (Narkar et al. 2008), most likely through the inhibition of ACC2 activity, which leads to reduced CPT1 activity, increased long-chain fatty acid entry into mitochondria, and increased fatty acid oxidation, although the mechanism remains uncertain and likely differs with chronic and acute treatment (Hoehn et al. 2010). Targeted ablation of
ACC2 in mice has resulted in a marked reduction in whole body adiposity (Abu-Elheiga et al. 2001), increased fatty acid oxidation coupled with elevated energy expenditure (Choi et al. 2007), or no net effect on energy balance or adiposity (Hoehn et al. 2010), depending on the line analyzed. The latter study (Hoehn et al. 2010) suggests that chronically 
A
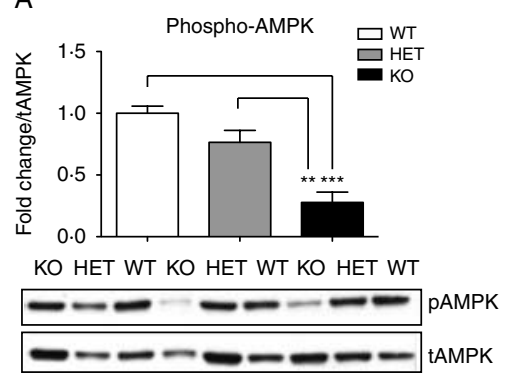

B
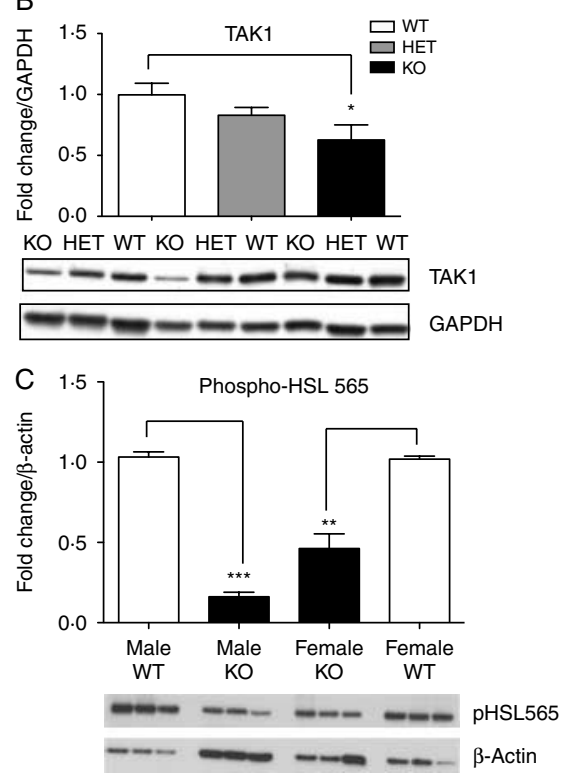

Figure 3 Phospho-AMPK, TAK1, and phospho-HSL (ser565) levels are decreased and PKA substrate phosphorylation is increased in Vgf knockout (KO) WAT. Phospho-AMPK (A), TAK1 (B), and phospho-HSL (ser565) (C) protein levels in gonadal WAT from $V g f+N g f+(\mathrm{WT})$, $V g f+N g f-(\mathrm{HET})$, and $V g f-N g f-(\mathrm{KO})$ mice were determined by western blotting, densitometry, and quantification using $\mathrm{NIH}$ image. Results were normalized to total AMPK (A), GAPDH (B), and $\beta$-actin (C and D). VGF ablation significantly decreased AMPK phosphorylation, TAK1 levels, and HSL (ser565) phosphorylation, in Vgf- $V g f$ - compared with $V g f+/ g f+$ WAT $(n=5-6$ mice of each genotype per group, mean \pm s.E.M.;

${ }^{* * *} P=0.0001 ;{ }^{* *} P=0.0053$ (A), ${ }^{* * P} P=0.0039$ (C); ${ }^{*} P=0 \cdot 0207$, ANOVA and Tukey's multiples comparison). In D, phosphorylation of PKA substrate in epididymal/gonadal WAT tissue from male and female $V g f-N g f-(n=3$ males and 5 females per group) and $V g f+$ $N g f+(n=3$ males and 4 females per group) mice was measured by western analysis. Values are mean \pm S.E.M. relative to the $V g f+N g f+$ control, normalized to $\beta$-actin. A significant increase in PKA substrate phosphorylation was noted $(* * P=0 \cdot 0072, * P=0 \cdot 0167)$ in male and female $V g f-N g f-$ WAT.

increased fatty acid oxidation, increased AMPK activity, and decreased ACC activity per se do not drive increased energy expenditure and reduced adiposity.

Our analysis of germline homozygous $V g f$ knockout mice here and previously (Watson et al. 2009), demonstrating increased whole body energy expenditure and increased uncoupling protein expression in BAT, together with decreased pAMPK, decreased pHSL (ser565), increased pHSL (ser563), and no change in ACC or pACC protein in WAT, are most consistent with an anti-lipolytic role for AMPK, and chronically stimulated lipolysis in Vgf knockout
WAT that is likely driven by increased SNS activity and $\beta$-adrenergic signaling. Decreased pAMPK levels in $V g f$ knockout WAT could be due to decreased TAK1 levels, an AMPK kinase, but may also reflect increased lipolysis and lowering of the AMP/ATP ratio in the adipocyte. Previous findings of increased serum-FFA levels in $V g f$ knockout mice are consistent with increased sympathetic outflow pathway activity and WAT lipolysis (Watson et al. 2005). In our analysis of protein levels in Vgf knockout WAT presented here, we noted several differences from previous studies of lipolytic enzyme mRNA levels in WAT (Watson et al. 2009). Increased 
Hsl (Lipe) and Fas mRNA levels and decreased Acc mRNA levels in knockout WAT (Watson et al. 2009) were not predictive of similar changes in protein levels (see Table 1). We previously found that increased mitochondrial number and UCP1 protein levels in $V g f$ knockout BAT were associated with decreased rather than increased $U_{c p} 1 \mathrm{mRNA}$ levels compared with wild-type (Watson et al. 2009). So although RNA levels often correlate with protein levels, greater understanding of the roles that specific gene products play in the regulation of metabolic flux ultimately relies on the determination of protein levels and activation state.

The VGF-derived peptide TLQP21 ( $\left.\mathrm{VGF}_{556-576}\right)$ robustly potentiates $\beta$-adrenergic receptor-induced lipolysis, increases sympathetic tone, increases energy expenditure, and prevents diet-induced obesity in mice (Bartolomucci et al. 2006, Possenti et al. 2012). This is somewhat paradoxical given the lean, hypermetabolic phenotype of germline $V g f$ knockout mice and our current and previous findings (Watson et al. 2005, 2009), which suggest increased sympathetic tone and lipolysis in these mice. Morphological alterations in WAT and BAT from $V g f$-deficient mice, including decreased lipid accumulation in WAT, smaller interscapular WAT depots that are associated with BAT, and regions of fat accretion in BAT, and increased fatty acid oxidation, increased UCP1 and UCP2 protein levels, and increased mitochondrial number and cristae density in BAT are consistent with increased SNS activity (Watson et al. 2005, 2009). Individual VGF-derived peptides may therefore have opposing activities, much as has been shown previously for the pro-opiomelanocortin (POMC)-derived peptides, $\alpha$-melanocyte stimulating hormone $(\alpha-\mathrm{MSH})$ and $\beta$-endorphin, which reduce and increase feeding respectively (Raffin-Sanson et al. 2003), while germline ablation of the Pomc gene in mice and humans leads to profound obesity (Yaswen et al. 1999). Moreover, increased feeding was found following intracranial administration of $\beta$-endorphin (Grandison \& Guidotti 1977), and also following selective ablation of the $\beta$-endorphin coding sequence from the mouse Pomc gene (Appleyard et al. 2003), a similarly paradoxical situation to the increased lipolysis noted in TLQP21-treated and $V g f$ knockout mice. Ablation of VGF-derived peptides other than TLQP21, including the neuroendocrine regulatory peptide-2 that regulates feeding and energy expenditure via an orexindependent mechanism, could therefore be responsible for the observed germline $V g f$ knockout phenotype (Toshinai et al. 2010). Alternatively, germline ablation of VGF could result in developmental abnormalities in hypothalamic/ sympathetic outflow pathways, or lack of this chromograninand secretogranin-like protein could impact dense core secretory vesicles structure and function, possibly altering catecholamine release from sympathetic terminals that innervate WAT, leading to chronic changes in $\beta$-adrenergic signaling. Additional experimentation using conditional knockout mice should allow these different hypotheses to be further tested.

\section{Declaration of interest}

The authors declare that there is no conflict of interest that could be perceived as prejudicing the impartiality of the research reported.

\section{Funding}

Supported in part by NIH Endocrine Training Grant 5T32DK07645 (S F); DK071308 and MH086499 (S R S); DK074873, DK083568, and DK082724 (C B); Diabetes Action Research and Education Foundation (S R S); Hope for Depression Research Foundation (S R S); ADA Basic Research Award (C B); and European Foundation for the Study of Diabetes Grant (T S). C B is the recipient of a Hirschl-Weill-Caulier Career Scientist Award.

\section{Author contribution statement}

S R S and C B designed the study; M S generated and genotyped the mice and assisted S F with sample preparation; S F, T S, and A C S carried out the protein analysis; S F, T S, C B, and S R S wrote the manuscript; all authors approved the final version of the manuscript.

\section{References}

Abu-Elheiga L, Matzuk MM, Abo-Hashema KA \& Wakil SJ 2001 Continuous fatty acid oxidation and reduced fat storage in mice lacking acetyl-CoA carboxylase 2. Science 291 2613-2616. (doi:10.1126/science. 1056843)

Anthonsen MW, Ronnstrand L, Wernstedt C, Degerman E \& Holm C 1998 Identification of novel phosphorylation sites in hormone-sensitive lipase that are phosphorylated in response to isoproterenol and govern activation properties in vitro. Journal of Biological Chemistry 273 215-221. (doi:10.1074/ jbc.273.1.215)

Anthony NM, Gaidhu MP \& Ceddia RB 2009 Regulation of visceral and subcutaneous adipocyte lipolysis by acute AICAR-induced AMPK activation. Obesity 17 1312-1317. (doi:10.1038/oby.2008.645)

Appleyard SM, Hayward M, Young JI, Butler AA, Cone RD, Rubinstein M \& Low MJ 2003 A role for the endogenous opioid $\beta$-endorphin in energy homeostasis. Endocrinology 144 1753-1760. (doi:10.1210/en.2002-221096)

Bachman ES, Dhillon H, Zhang CY, Cinti S, Bianco AC, Kobilka BK \& Lowell BB 2002 betaAR signaling required for diet-induced thermogenesis and obesity resistance. Science 297 843-845. (doi:10.1126/science.1073160)

Bartolomucci A, La Corte G, Possenti R, Locatelli V, Rigamonti AE, Torsello A, Bresciani E, Bulgarelli I, Rizzi R, Pavone F et al. 2006 TLQP-21, a VGF-derived peptide, increases energy expenditure and prevents the early phase of diet-induced obesity. PNAS 103 14584-14589. (doi:10.1073/pnas. 0606102103)

Bartolomucci A, Possenti R, Mahata SK, Fischer-Colbrie R, Loh YP \& Salton SR 2011 The extended granin family: structure, function, and biomedical implications. Endocrine Reviews 32 755-797. (doi:10.1210/ er.2010-0027)

Bergen HT, Mizuno TM, Taylor J \& Mobbs CV 1998 Hyperphagia and weight gain after gold-thioglucose: relation to hypothalamic neuropeptide Y and proopiomelanocortin. Endocrinology 139 4483-4488. (doi:10.1210/ en.139.11.4483)

Bray GA \& York DA 1998 The MONA LISA hypothesis in the time of leptin. Recent Progress in Hormone Research 53 95-117 (discussion 117-118).

Choi CS, Savage DB, Abu-Elheiga L, Liu ZX, Kim S, Kulkarni A, Distefano A, Hwang YJ, Reznick RM, Codella R et al. 2007 Continuous fat oxidation in acetyl-CoA carboxylase 2 knockout mice increases total energy expenditure, reduces fat mass, and improves insulin sensitivity. PNAS 104 16480-16485. (doi:10.1073/pnas.0706794104) 
Collins S, Cao W \& Robidoux J 2004 Learning new tricks from old dogs: $\beta$-adrenergic receptors teach new lessons on firing up adipose tissue metabolism. Molecular Endocrinology 18 2123-2131. (doi:10.1210/me. 2004-0193)

Daval M, Diot-Dupuy F, Bazin R, Hainault I, Viollet B, Vaulont S, Hajduch E, Ferre P \& Foufelle F 2005 Anti-lipolytic action of AMP-activated protein kinase in rodent adipocytes. Journal of Biological Chemistry $28025250-25257$. (doi:10.1074/jbc.M414222200)

Fan W, Dinulescu DM, Butler AA, Zhou J, Marks DL \& Cone RD 2000 The central melanocortin system can directly regulate serum insulin levels. Endocrinology 141 3072-3079. (doi:10.1210/en.141.9.3072)

Foster MT, Song CK \& Bartness TJ 2010 Hypothalamic paraventricular nucleus lesion involvement in the sympathetic control of lipid mobilization. Obesity 18 682-689. (doi:10.1038/oby.2009.345)

Friedman JM \& Halaas JL 1998 Leptin and the regulation of body weight in mammals. Nature 395 763-770. (doi:10.1038/27376)

Gaidhu MP, Fediuc S, Anthony NM, So M, Mirpourian M, Perry RL \& Ceddia RB 2009 Prolonged AICAR-induced AMP-kinase activation promotes energy dissipation in white adipocytes: novel mechanisms integrating HSL and ATGL. Journal of Lipid Research 50 704-715. (doi:10.1194/jlr.M800480-JLR200)

Giordano A, Frontini A, Murano I, Tonello C, Marino MA, Carruba MO, Nisoli E \& Cinti S 2005 Regional-dependent increase of sympathetic innervation in rat white adipose tissue during prolonged fasting. Journal of Histochemistry and Cytochemistry 53 679-687. (doi:10.1369/ jhc.4A6566.2005)

Grandison L \& Guidotti A 1977 Stimulation of food intake by muscimol and $\beta$ endorphin. Neuropharmacology 16 533-536. (doi:10.1016/00283908(77)90019-3)

Greenberg AS, Shen WJ, Muliro K, Patel S, Souza SC, Roth RA \& Kraemer FB 2001 Stimulation of lipolysis and hormone-sensitive lipase via the extracellular signal-regulated kinase pathway. Journal of Biological Chemistry 276 45456-45461. (doi:10.1074/jbc.M104436200)

Gruber A, Cornaciu I, Lass A, Schweiger M, Poeschl M, Eder C, Kumari M, Schoiswohl G, Wolinski H, Kohlwein SD et al. 2010 The N-terminal region of comparative gene identification-58 (CGI-58) is important for lipid droplet binding and activation of adipose triglyceride lipase. Journal of Biological Chemistry 285 12289-12298. (doi:10.1074/ jbc.M109.064469)

Hahm S, Mizuno TM, Wu TJ, Wisor JP, Priest CA, Kozak CA, Boozer CN, Peng B, McEvoy RC, Good P et al. 1999 Targeted deletion of the Vgf gene indicates that the encoded secretory peptide precursor plays a novel role in the regulation of energy balance. Neuron 23 537-548. (doi:10.1016/S0896-6273(00)80806-5)

Hahm S, Fekete C, Mizuno TM, Windsor J, Yan H, Boozer CN, Lee C, Elmquist JK, Lechan RM, Mobbs CV et al. 2002 VGF is required for obesity induced by diet, gold thioglucose treatment and agouti, and is differentially regulated in POMC- and NPY-containing arcuate neurons in response to fasting. Journal of Neuroscience 22 6929-6938.

Hoehn KL, Turner N, Swarbrick MM, Wilks D, Preston E, Phua Y, Joshi H, Furler SM, Larance M, Hegarty BD et al. 2010 Acute or chronic upregulation of mitochondrial fatty acid oxidation has no net effect on whole-body energy expenditure or adiposity. Cell Metabolism 11 70-76. (doi:10.1016/j.cmet.2009.11.008)

Lass A, Zimmermann R, Haemmerle G, Riederer M, Schoiswohl G, Schweiger M, Kienesberger P, Strauss JG, Gorkiewicz G \& Zechner R 2006 Adipose triglyceride lipase-mediated lipolysis of cellular fat stores is activated by CGI-58 and defective in Chanarin-Dorfman syndrome. Cell Metabolism 3 309-319. (doi:10.1016/j.cmet.2006.03.005)

Levi A, Ferri GL, Watson E, Possenti R \& Salton SR 2004 Processing, distribution and function of VGF, a neuronal and endocrine peptide precursor. Cellular and Molecular Neurobiology 24 517-533. (doi:10.1023/ B:CEMN.0000023627.79947.22)

Li G, Mobbs CV \& Scarpace PJ 2003 Central pro-opiomelanocortin gene delivery results in hypophagia, reduced visceral adiposity, and improved insulin sensitivity in genetically obese Zucker rats. Diabetes 52 1951-1957. (doi:10.2337/diabetes.52.8.1951)
Momcilovic M, Hong SP \& Carlson M 2006 Mammalian TAK1 activates Snf1 protein kinase in yeast and phosphorylates AMP-activated protein kinase in vitro. Journal of Biological Chemistry 281 25336-25343. (doi:10.1074/jbc.M604399200)

Morris MJ, Tortelli CF, Filippis A \& Proietto J 1998 Reduced BAT function as a mechanism for obesity in the hypophagic, neuropeptide $\mathrm{Y}$ deficient monosodium glutamate-treated rat. Regulatory Peptides 75-76 441-447. (doi:10.1016/S0167-0115(98)00100-1)

Murano I, Barbatelli G, Giordano A \& Cinti S 2009 Noradrenergic parenchymal nerve fiber branching after cold acclimatisation correlates with brown adipocyte density in mouse adipose organ. Journal of Anatomy 214 171-178. (doi:10.1111/j.1469-7580.2008.01001.x)

Narkar VA, Downes M, Yu RT, Embler E, Wang YX, Banayo E, Mihaylova MM, Nelson MC, Zou Y, Juguilon H et al. 2008 AMPK and PPARdelta agonists are exercise mimetics. Cell 134 405-415. (doi:10.1016/j.cell.2008.06.051)

Penn DM, Jordan LC, Kelso EW, Davenport JE \& Harris RB 2006 Effects of central or peripheral leptin administration on norepinephrine turnover in defined fat depots. American Journal of Physiology. Regulatory, Integrative and Comparative Physiology 291 R1613-R1621. (doi:10.1152/ajpregu. 00368.2006)

Possenti R, Muccioli G, Petrocchi P, Cero C, Cabassi A, Vulchanova L, Riedl MS, Manieri M, Frontini A, Giordano A et al. 2012 Characterization of a novel peripheral pro-lipolytic mechanism in mice: role of VGF-derived peptide TLQP-21. Biochemical Journal 441 511-522. (doi:10.1042/BJ20111165)

Raffin-Sanson ML, de Keyzer Y \& Bertagna X 2003 Proopiomelanocortin, a polypeptide precursor with multiple functions: from physiology to pathological conditions. European Journal of Endocrinology 149 79-90. (doi:10.1530/eje.0.1490079)

Salton SR, Ferri GL, Hahm S, Snyder SE, Wilson AJ, Possenti R \& Levi A 2000 VGF: a novel role for this neuronal and neuroendocrine polypeptide in the regulation of energy balance. Frontiers in Neuroendocrinology 21 199-219. (doi:10.1006/frne.2000.0199)

Scherer T, O’Hare J, Diggs-Andrews K, Schweiger M, Cheng B, Lindtner C, Zielinski E, Vempati P, Su K, Dighe S et al. 2011 Brain insulin controls adipose tissue lipolysis and lipogenesis. Cell Metabolism 13 183-194. (doi:10.1016/j.cmet.2011.01.008)

Song CK, Jackson RM, Harris RB, Richard D \& Bartness TJ 2005 Melanocortin-4 receptor mRNA is expressed in sympathetic nervous system outflow neurons to white adipose tissue. American Journal of Physiology. Regulatory, Integrative and Comparative Physiology 289 R1467-R1476. (doi:10.1152/ajpregu.00348.2005)

Souza SC, Muliro KV, Liscum L, Lien P, Yamamoto MT, Schaffer JE, Dallal GE, Wang X, Kraemer FB, Obin M et al. 2002 Modulation of hormone-sensitive lipase and protein kinase A-mediated lipolysis by perilipin A in an adenoviral reconstituted system. Journal of Biological Chemistry 277 8267-8272. (doi:10.1074/jbc.M108329200)

Subramanian V, Rothenberg A, Gomez C, Cohen AW, Garcia A, Bhattacharyya S, Shapiro L, Dolios G, Wang R, Lisanti MP et al. 2004 Perilipin A mediates the reversible binding of CGI-58 to lipid droplets in 3T3-L1 adipocytes. Journal of Biological Chemistry $27942062-42071$. (doi:10.1074/jbc.M407462200)

Toshinai K, Yamaguchi H, Kageyama H, Matsuo T, Koshinaka K, Sasaki K, Shioda S, Minamino N \& Nakazato M 2010 Neuroendocrine regulatory peptide-2 regulates feeding behavior via the orexin system in the hypothalamus. American Journal of Physiology. Endocrinology and Metabolism 299 E394-E401. (doi:10.1152/ajpendo.00768.2009)

Tsukahara F, Uchida Y, Ohba K, Ogawa A, Yoshioka T \& Muraki T 1998 The effect of acute cold exposure and norepinephrine on uncoupling protein gene expression in brown adipose tissue of monosodium glutamate-obese mice. Japanese Journal of Pharmacology 77 247-249. (doi:10.1254/jjp.77.247) Valenzuela DM, Murphy AJ, Frendewey D, Gale NW, Economides AN, Auerbach W, Poueymirou WT, Adams NC, Rojas J, Yasenchak J et al. 2003 High-throughput engineering of the mouse genome coupled with high-resolution expression analysis. Nature Biotechnology 21 652-659. (doi:10.1038/nbt822) 
Voss-Andreae A, Murphy JG, Ellacott KL, Stuart RC, Nillni EA, Cone RD \& Fan W 2007 Role of the central melanocortin circuitry in adaptive thermogenesis of brown adipose tissue. Endocrinology 148 1550-1560. (doi:10.1210/en.2006-1389)

Watson E, Hahm S, Mizuno TM, Windsor J, Montgomery C, Scherer PE, Mobbs CV \& Salton SR 2005 VGF ablation blocks the development of hyperinsulinemia and hyperglycemia in several mouse models of obesity. Endocrinology 146 5151-5163. (doi:10.1210/en.2005-0588)

Watson E, Fargali S, Okamoto H, Sadahiro M, Gordon RE, Chakraborty T, Sleeman MW \& Salton SR 2009 Analysis of knockout mice suggests a role for VGF in the control of fat storage and energy expenditure. BMC Physiology 9 19. (doi:10.1186/1472-6793-9-19)

Xie M, Zhang D, Dyck JR, Li Y, Zhang H, Morishima M, Mann DL, Taffet GE, Baldini A, Khoury DS et al. 2006 A pivotal role for endogenous TGF- $\beta$-activated kinase-1 in the LKB1/AMP-activated protein kinase energy-sensor pathway. PNAS 103 17378-17383. (doi:10.1073/pnas.0604708103)

Yaswen L, Diehl N, Brennan MB \& Hochgeschwender U 1999 Obesity in the mouse model of pro-opiomelanocortin deficiency responds to peripheral melanocortin. Nature Medicine 5 1066-1070. (doi:10.1038/12506)

Received in final form 9 August 2012

Accepted 31 August 2012

Made available online as an Accepted Preprint 31 August 2012 